Goldschmidt 2021 Abstract

https://doi.org/10.7185/gold2021.6360

\section{Sub-micrometer pyrites in microbialites record equilibrium $S$ isotope fractionation by Microbial Sulfate Reduction independently of the sulfate concentration of the water}

\author{
JOHANNA MARIN-CARBONNE ${ }^{1}$, MARIE-NOËLLE
}

DECRAENE ${ }^{1}$, LAURENT REMUSAT ${ }^{2}$, ROBIN HAVAS ${ }^{3}$, DR. CHRISTOPHE THOMAZO ${ }^{3}$, MR. VIRGIL PASQUIER, PHD $^{4}$, JULIEN ALLEON ${ }^{1}$, NINA ZEYEN ${ }^{5}$, SYLVAIN BERNARD ${ }^{2}$, STÉPHANE ESCRIG ${ }^{6}$, EMMANUELLE VENNIN ${ }^{7}$, ANDERS MEIBOM $^{6}$ AND KARIM BENZERARA ${ }^{2}$

${ }^{1}$ Université de Lausanne

${ }^{2}$ IMPMC CNRS/Sorbonne Université/MNHN

${ }^{3}$ Biogéosciences, CNRS UMR 6282, Université de Bourgogne Franche-Comté

${ }^{4}$ Weizmann Institute of Science

${ }^{5}$ University of Alberta - EAS

${ }^{6}$ École polytechnique fédérale de Lausanne

${ }^{7}$ University of Bourgogne Franche-Comté

Presenting Author: johanna.marincarbonne@unil.ch

Microbial mats are composed of diverse layered microbial communities spreading across strong geochemical and redox gradients. The relationships between the diverse microbial metabolic activities and the isotopic signatures in associated biominerals within these mats are key to understand the modern biogeochemical cycle(s), but also to interpret the geological record. While previous studies have documented in detail the locus of sulfate reduction processes, through identification of soluble sulfur species captured using silver disks, very few have analyzed individual pyrite grains within the microbial mats. Here we present detailed mineralogy coupled with NanoSIMS analyses of pyrite S-isotope analyses in two different microbialites, from a hypersaline lagoonal environment (Cayo Coco, Cuba) and a volcanic alkaline lake (Atexcac, Mexico). They have very different water chemistries, including sulfate concentrations. The microbial deposits from both localities exhibit two distinct pyrite morphologies: framboids, with sizes ranging from 2 to $15 \mu \mathrm{m}$, and micropyrites with dimensions less than $3 \mu \mathrm{m}$. Textural observation by electron microscopy suggested that the micropyrites are syngenetic of biofilm mineralization, while framboidal pyrite are formed secondarily. Framboids displayed $\delta^{34} \mathrm{~S}$ values from -45 to $-10 \%$ (average of $-19.5 \pm 5 \%$ and $-26.1 \pm 6 \%$ for Cayo Coco and Atexcac respectively), while micropyrites were characterized by distinctly lighter sulfur isotopic compositions with $\delta^{34} \mathrm{~S}$ between -86 to -17 $\%$ (average of $-34.5 \pm 29 \%$ and $-61.3 \pm 17 \%$ o for Cayo Coco and Atexcac respectively). The large range of $\delta^{34} \mathrm{~S}$ values recorded in individually framboidal pyrites is consistent with a Raleigh distillation process. Considering respective sulfate isotopic composition of the two environments, micropyrites display similar $\Delta_{\text {pyr }}$ (i.e. $\Delta_{\text {pyr }} \equiv \delta^{34} \mathrm{~S}_{\mathrm{SO} 4}-\delta^{34} \mathrm{~S}_{\text {pyr }}$ ), ranging from 56 to $62 \%$ independently of sulfate concentration (i.e 62 to $2.1 \mathrm{mM}$ ). Our reconstructed $\Delta_{\text {pyr }}$ are compatible with the equilibrium fractionation associated with low respiration rates of microbial sulfate reduction in natural settings. This result highlights the potential for micropyrites preserved in geological record as biosignature from ancient microbial sulfate reduction but also challenges the robustness of using bulk $\Delta_{\text {pyr }}$ for reconstructing secular evolution of sulfate concentration through Earth history.

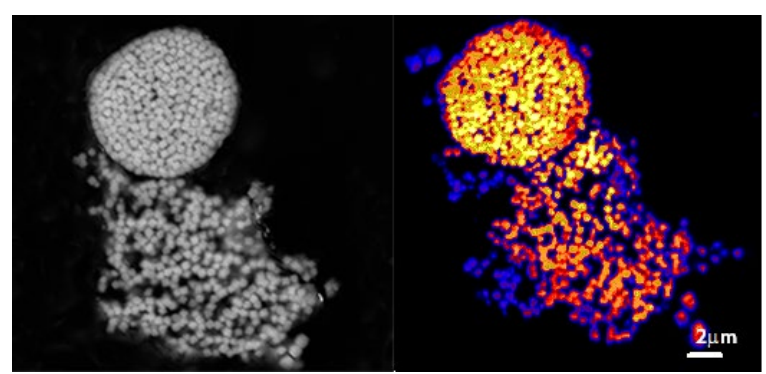

